\title{
Characterization and modeling of cooling and drying of pellets for animal feed
}

\author{
Charlène Lambert $^{\mathrm{a}}$, Julien Cartailler ${ }^{\mathrm{a}}$, Sandy Rouchouse ${ }^{\mathrm{b}}$, Giana Almeida ${ }^{\mathrm{a}}$, Francis Courtois ${ }^{\mathrm{a}, *}$ \\ ${ }^{a}$ UMR Ingéniérie Procédés Aliments, AgroParisTech, Inra, Université Paris Saclay, 91300 Massy, France \\ ${ }^{b}$ Tecaliman (technical center), F-44316 Nantes Cedex 3, France
}

\begin{abstract}
The process used to produce pellets for animal feed, especially the drying-cooling step, has not been extensively explored in the literature. However, with the increased industrial use of adjustable-speed drives to reduce fan energy consumption, the need for reliable simulation models has increased. In this work, different formulations of pellets were characterized and both their drying and drying-cooling kinetics were modeled. In comparing the results of the simulations with experimental results, the observed discrepancies were similar to the experimental uncertainties, indicating that our prediction tools yielded imperfect but acceptable results both in the thin-layer and deep-bed drying configurations. Furthermore, the approach centered on drying kinetics was also able to predict drying-cooling kinetics. This work suggests that one simple EMC equation, without temperature dependency, may correctly fit the behavior of several kinds of pellets and be sufficient for accurate simulations. The overall approach may be easily applied to many other kinds of pellets.
\end{abstract}

Keywords: cooling, drying, pellets, animal feed, characterization, model

\section{Introduction}

The process by which pellets are manufactured consists of several steps: grinding, weighing raw materials, mixing, pelleting to agglomerate small particles into larger ones, cooling, and conditioning. Despite its economic importance, this process has been largely ignored in the literature, with only a few exceptions. The limited research conducted to date has mainly focused on the effect of pellet formulation on the manufacturing process (Wood, 1987, Thomas \& van der Poel, 1996, Thomas et al., 1998, Hemmingsen et al., 2008), or the conditioning (Thomas et al. 1997) or pelleting (Thomas et al., 1997, de Blank et al., 1997) steps of the process.

\footnotetext{
* Francis Courtois

Email addresses: charlene.lambert@agroparistech.fr (Charlène Lambert), julien.cartailler@agroparistech.fr (Julien Cartailler), s.rouchouse@tecaliman.com (Sandy Rouchouse), giana.perre@agroparistech.fr (Giana Almeida), francis.courtois@agroparistech.fr (Francis Courtois)
} 
Even if cooling is not one of the most energy-consuming steps of this process, industrial investment has Arkema, 1992) and its simulations were validated at a pilot scale. However, this model was only able to predict the trend of moisture and temperature effects on cooler performance (Kelley et al., 1990; Maier \& Bakker-Arkema, 1992; Maier et al., 1992) and did not accurately predict moisture loss and temperature in pellets (up to $60 \%$ deviation was observed between experimental and simulated data). Hence, what is needed pellet formulation on operating conditions. Ideally, such a model would also be able to take into account changes in pellet composition, as pellet recipes are changed continuously in response to variations in the cost of ingredients (soya, corn, etc.). These changes are likely to affect drying-cooling performance and represent a challenge to model development.

The purpose of this work was to develop a convective drying-cooling model that could be implemented in two versions: 1) an unsteady-state version, in order to control process parameters, and 2) a steady- 
state version, in computer-aided engineering (CAE) software. In a recent work discussing classical modeling approaches of convective drying processes (Lambert et al. 2015a), it was argued that the main characteristics of a successful model should be a low computational requirement and a wide range of validity. Simulation of the drying or drying-cooling operation should not last longer than a few seconds, and the model should also have multi-product compatibility and extrapolation capability. It should be able to simulate all classical drying and drying-cooling conditions. In addition, it should allow the late addition of new products or at least new formulations without the need to modify the equations. Thus, parameters of the model should have a physical meaning and should be calculated with correlations, experimentally measured, or identified by reverse methods (Lambert et al. 2015a).

The aim of our model was to predict the final moisture content of pellets and the energy consumption of the drying-cooling process. However, obtaining reliable drying-cooling kinetics is difficult, especially in the thin-layer configuration. Hence, we decided to first focus on a drying-only model. We then attempted to validate this model using deep-bed cooling-drying kinetics.

\section{Materials and methods}

There is almost an infinite number of formulations of animal feed pellets. This study focused on the experimental characterization of two formulations, with various recipes and pelleting conditions. Water activity and effective moisture diffusivity were identified using DVS data and drying kinetics, respectively.

\subsection{Origin of the pellets}

The two formulations of animal feed pellets studied were pellets for chickens (P4C) and for rabbits (P4R). In the latter case, we studied two different geometries of the same composition (same raw materials and recipe). These were designated $\mathrm{P} 4 \mathrm{R}-2.5 \mathrm{~mm}$ and $\mathrm{P} 4 \mathrm{R}-4 \mathrm{~mm}$. All formulations had a cylindrical shape. Raw seed composition and dry matter composition of both pellet formulations are given in tables 1 and 2 respectively. For the pelleting process, ingredients were mixed with steam in a conditioner then

${ }_{65}$ pelleted in a press. The temperatures of the pellets at the press outlet were $84^{\circ} \mathrm{C}(\mathrm{P} 4 \mathrm{C}), 87^{\circ} \mathrm{C}(\mathrm{P} 4 \mathrm{R}-2.5$ $\mathrm{mm})$, and $83^{\circ} \mathrm{C}(\mathrm{P} 4 \mathrm{R}-4 \mathrm{~mm})$. The pellet moisture content at the press outlet was 0.204 d.b. (P4C), 0.211 d.b. (P4R - $2.5 \mathrm{~mm})$, and 0.202 d.b. (P4R - $4 \mathrm{~mm})$. For each formulation and geometry, 2.5-kg samples of pellets were vacuum-packed in plastic boxes and later stored in a cold room.

\subsection{Moisture content measurement}

Pellet moisture content was measured according to the French AFNOR norm NF V 18-109, before thinlayer and deep-bed drying and after thin-layer drying. The pellets were first ground using a water-cooled 
miller (IKA WERKE KM 20). The measurement method assumes a weight loss of $5.00 \mathrm{~g}( \pm 0.05 \mathrm{~g})$ of pellet powder during a 4 -hour stay in a $103^{\circ} \mathrm{C}$ oven. Samples were then placed in a desiccator for at least 1 hour before being weighed. The moisture content was averaged over three samples.

\subsection{Geometry measurement}

Apparent density of pellet dry matter was measured using Fontainebleau sand. Real density of pellet dry matter was determined using an air pycnometer (ACCUPYC 1330). Pellet dimensions were measured using two methods: a manual approach using a caliper and an automated approach based on image analysis (using a flatbed scanner and ImageJ software). Porosity of the bed was determined according to equation 1

$$
\varepsilon=\frac{\rho_{d m}^{r e a l}-\rho_{d m}^{a p}}{\rho_{d m}^{r}}
$$

where $\varepsilon$ is the bed porosity (decimal), $\rho_{d m}^{r e a l}$ the real density of the dry matter $\left(\mathrm{kg} \cdot \mathrm{m}^{-3}\right)$ and $\rho_{d m}^{a p}$ the apparent density of the dry matter $\left(\mathrm{kg} \cdot \mathrm{m}^{-3}\right)$.

\subsection{Sorption isotherm measurement}

Isothermal analyses were performed using a DVS Intrinsic apparatus (Surface Measurement Systems, London, UK). An ultra-sensitive micro-balance enabled the measurement of mass variations as small as 1 part per 10 million. First, samples were ground using a water-cooled miller (IKA WERKE KM 20). Approximately $10 \mathrm{mg}$ of each sample was inserted in the pan. In the DVS device, a constant flow of nitrogen gas was mixed with a preset amount of water vapor. Nitrogen then passed through the chamber to maintain the desired relative humidity level, $\pm 0.5 \%$. All sorption cycles started with $0 \%$ relative humidity $(\mathrm{RH})$. The dry matter was determined from values obtained after the plateau was reached. Isotherms were measured at two different temperatures for $\mathrm{P} 4 \mathrm{Cs}\left(25^{\circ} \mathrm{C}\right.$ and $\left.40^{\circ} \mathrm{C}\right)$ and at $25^{\circ} \mathrm{C}$ for P4Rs; P4R measurements were performed in duplicate. Adsorption/desorption cycles of relative humidity $(\mathrm{RH})$ looped from $0 \%$ up to $90 \%$ then back down to $0 \%$, by steps of $10 \% \mathrm{RH}$. In experiments at $40^{\circ} \mathrm{C}, 92.3 \% \mathrm{RH}( \pm 0.4 \% \mathrm{RH})$ was measured instead of $90 \% \mathrm{RH}$ due to inadequate performance of the $\mathrm{RH}$ control loop. All reported results were based on actual measured $\mathrm{RH}$ values (which occasionally differed from target values). The instrument maintained a constant $\mathrm{RH}$ until the change in sample moisture content was less than $0.002 \%$ per minute over a 10-min period. This threshold value was obtained from Hill et al. (2009), in order to obtain a final sample moisture content within $0.1 \%$ of the equilibrium value over an extended period of time.

Equilibrium moisture content $\left(X_{e q}\right)$ and relative humidity $(\mathrm{RH}) /$ water activity $\left(a_{w}\right)$ data were fitted using a modified Henderson equation (equation 2) (Henderson, 1952, Thompson, 1968) without temperature dependency and the Chung-Pfost correlation (equation 3) (Chung \& Pfost, 1967). The Henderson equation 
is one of the five equations recommended by ASAE Standard D245.6 for fitting sorption data from several agri-food materials (ASAE, 2007). The Chung-Pfost correlation was used by (Maier \& Bakker-Arkema, 1992 ) and (Brook \& Foster, 1981) but, as will be discussed later, this equation (3) cannot guarantee that when $X_{e q}=0$ then $a_{w}=0$, which is a major flaw for simulators.

$$
\begin{gathered}
a_{w}=1-\exp \left(-p_{1} \cdot\left(X_{e q}\right)^{p_{2}}\right) \\
X_{e q}=p_{1}-p_{2} \cdot \ln \left(-p_{3} \cdot\left(\Theta+p_{4}\right) \cdot \ln \left(a_{w}\right)\right)
\end{gathered}
$$

105

The precision of measurements of mean moisture content was estimated for each formulation of pellets by repeating measurements of thin-layer kinetics. The following uncertainties were determined: - P4C: \pm 0.015 d.b. $(\sigma=0.005$ d.b. $)$;

where $p_{1}-p_{4}$ are constants that need to be identified using experimental data, $X_{e q}$ is the equilibrium moisture content (\% d.b.), and $\Theta$ is the product surface temperature $\left({ }^{\circ} \mathrm{C}\right)$.

\subsection{Drying experiment}

Pellets were dried using two different protocols: a conventional hot-air drying approach (i.e. several thin layer kinetics and one deep bed kinetic) and a drying-cooling method (deep-bed kinetics only). Measurements of thin-layer kinetics were performed in triplicate. For both methods, experimental data were recorded using an automated pilot dryer located in an AgroParisTech/INRA drying laboratory (Massy, France) under constant conditions (see below).

\subsubsection{Description of the drying pilot}

A schematic of the drying pilot is given in figure 1. In this pilot, the air passes, from the top to the bottom, through a cylindrical drying chamber $(25 \mathrm{~cm}$ in diameter and $28 \mathrm{~cm}$ in height). The following variables were recorded every minute (with an OPTO22 SNAP-PAC-EB2 data logger):

- inlet and outlet air temperatures (with T-type thermocouples and platinium probes) and relative humidities (with VAISALA $135 \mathrm{Y}$ and ROTRONIC HF532-HC2 probes);

- inlet air velocity (using an ANNUBAR ANR-73 Pitot tube and a FURNESS FCO-53 differential pressure sensor);

- mass of the product (with a METTLER PE 16 discontinuous weighing system with air bypassed). 
- $\mathrm{P} 4 \mathrm{R}-2.5 \mathrm{~mm}$ and $\mathrm{P} 4 \mathrm{R}-4 \mathrm{~mm}: \pm 0.018$ d.b. $(\sigma=0.06$ d.b. $)$.

For measurements of relative humidity and temperature in the pilot dryer, the following uncertainties (using $\pm 3 \sigma)$ were determined:

- Inlet air temperature: $\pm 1.5^{\circ} \mathrm{C}\left(\sigma=0.5^{\circ} \mathrm{C}\right)$;

- Outlet air temperature: $\pm 2.5^{\circ} \mathrm{C}\left(\sigma=0.8^{\circ} \mathrm{C}\right)$;

- Inlet and outlet relative humidities: $\pm 5 \%(\sigma=1.7 \%)$

However, actual deviations in measurements of outlet air temperature and relative humidity may have been greater than those estimated here, for three reasons. First, due to the intermittent nature of the mass measurement system, minor air leaks and locally reduced thermal insulation below the sieve were unavoidable. Second, it is possible that having the sensor close to the sieve introduced bias due to thermal radiation. Finally, due to the depth of the beds, air flow below the sieve was less homogeneous. Because of this, the outlet air temperature may have been slightly underestimated. In addition, the response time of the relative humidity sensor ( $45 \mathrm{~s}$ ) was not negligible compared to the sudden variations in relative humidity in the first minutes of the drying process. As a consequence, a comparison of experimental and simulated data during this initial period was undertaken very carefully (see discussion).

\subsubsection{Drying and drying-cooling protocols}

Drying method. Thin-layer and deep-bed drying kinetics were recorded using P4Cs and P4Rs (P4R - 4 mm and P4R - $2.5 \mathrm{~mm}$ ). About $200 \mathrm{~g}$ (thin layers) and between 2.5 to $5 \mathrm{~kg}$ (deep beds approximately 0.10- to $0.20-\mathrm{m}$ high) of pellets were introduced into the dryer. Operating conditions of the dryer are summarized in table 3 .

Drying-cooling method. As stated in the introduction, it is quite difficult to precisely control the initial conditions of the pellets entering the drying-cooling experiment. It takes considerable effort to warm up the pellets without drying them and then transfer them to the dryer without the premature loss of water or heat. Even when this can be done, it is extremely challenging to then obtain accurate measurements of the actual initial product temperature and moisture content at the beginning of the drying-cooling step. In this work, no reliable data could be obtained for thin-layer drying-cooling kinetics, hence, the only drying-cooling data available were for the deep-bed drying kinetics of P4Cs. About $5 \mathrm{~kg}$ of pellets were vacuum-packed using a vacuum heat sealer (MULTIVALUED GASTRONOMIC) and pouches composed of low-density polyethylene (LEXINGTON). Packing pellets in a vacuum-sealed bag limited pellets' contact with air and minimized mass transfers during preheating. The pellets and the sieve were then pre-heated as follows: 
- The sieve of the dryer was preheated to about $100^{\circ} \mathrm{C}$ using a heat gun (METABO H 1600) in order to be at nearly $80^{\circ} \mathrm{C}$ at the beginning of the experiment;

- Pellets, in their vacuum-sealed bags, were pre-heated in a $100^{\circ} \mathrm{C}$ oven for one hour. The core temperature of the pellets was about $60-70^{\circ} \mathrm{C}$ when taken out of the oven.

Pellets were then introduced into the drying zone after stabilization of the dryer's operating conditions (tested conditions are listed in table 31). A sub-sample was withdrawn for moisture content measurement. The initial temperature of the pellets was initially estimated through the use of an infrared thermometer, but these measurements were not used because of suspected bias. A better estimate was obtained from the recorded outlet air temperature after two minutes of drying-cooling.

\subsection{Identification of $D_{\text {eff }}$}

This study continues previous work that discussed three different approaches for the identification of effective moisture diffusivity $D_{\text {eff }}$. (Lambert et al., 2015b). Here, these three strategies were used for the identification of the effective moisture diffusivity of pellets as summarized in table 4

As a reminder, the classical strategy used in food drying consists of four steps:

1. Measure in the laboratory the accessible properties of the product (water activity, heat capacity, geometry, and porosity);

2. Collect experimental measurements of thin-layer drying kinetics under constant air drying conditions over a wide range of air temperatures;

3. Identify the effective moisture diffusivity coefficient by fitting a model to these thin-layer drying kinetics (using variations of recorded product moisture content);

4. Validate the model using some thin-layer (using product moisture content) and/or deep-bed drying kinetics (using product moisture content and possibly output air moisture and temperature).

This strategy was used to identify the effective moisture diffusivity of P4Rs - $2.5 \mathrm{~mm}$. The validation set contained both thin-layer and deep-bed drying kinetics. As explained in a previous study (Lambert et al. 2015b), in this strategy, the mass variation of the product is the only experimental data used to identify the effective moisture diffusivity. However, using only mass-transfer-related information is problematic since, in drying, this transfer is strongly coupled to energy change. In a deep-bed experiment, though, inlet and outlet air temperatures and relative humidities may be recorded in order to provide energy-related data (Lambert et al., 2015b). By providing data on both heat and mass transfers, an approach based on deepbed drying kinetics brings far more information to the identification procedure compared to those based on several measurements of thin-layer kinetics. With this in mind, the two other developed strategies were 
derived from the classical one, but with a major difference: effective moisture diffusivity was identified using deep-bed drying kinetics as opposed to thin-layer kinetics Lambert et al. (2015b). In the first approach, the identification set contained drying kinetics from a single deep-bed setup, obtained at a high temperature $\left(90^{\circ} \mathrm{C}\right)$. The validation set contained both thin-layer drying kinetics and a set of deep-bed drying-cooling

The heat and mass Biot values $\left(B i_{h}\right.$ and $\left.B i_{m}\right)$ were, respectively, between 0.1 and 100 and much higher
than 100. Therefore, heat conduction and liquid water diffusion within the particles were considered, along

The heat and mass Biot values $\left(B i_{h}\right.$ and $\left.B i_{m}\right)$ were, respectively, between 0.1 and 100 and much higher
than 100. Therefore, heat conduction and liquid water diffusion within the particles were considered, along

where $d_{1}$ and $d_{2}$ are constants that are optimized to force the simulation to best fit the experimental data.

\section{Modeling of drying-cooling}

In order to develop a versatile food-drying simulation, we selected the following compromise among the different approaches, published in a previous work (Lambert et al. 2015a), and considered some major assumptions. A convective drying model was created for both deep-bed and thin-layer configurations. One usually treats the deep bed as a series of thin layers for which the only transfer occurs between air and grain, and a thin layer as an equivalent single (average) particle. Moreover, deep-bed drying involves energy and mass transfers in the air, after each thin layer crossing (Courtois, 1991).

\subsection{Heat and mass balances}

\subsubsection{For the particles}

The following assumptions were considered for the particles:

- Ideal geometry (infinite cylinder or spherical shape) with negligible shrinkage or swelling;

- Isotropic behavior (heat and mass transfers only in the radial direction);

- Negligible heat conduction between particles; 
with water evaporation, heat convection, and mass convection at their surfaces (Bird et al., 2002). The heat and mass Peclet values $\left(P e_{h}\right.$ and $\left.P e_{m}\right)$ were much higher than 1, so a plug-type airflow and negligible pressure variation were assumed (Bird et al., 2002). Heat and mass balances for the particles, liquid water diffusion (equation 5) and thermal conduction (equation 6) phenomena were based on Fick's and Fourier's law, respectively (Bird et al., 2002).

$$
\begin{gathered}
\frac{d X_{t}^{r, z}}{d t}=\frac{1}{r^{n}} \cdot \frac{\partial}{\partial r}\left(r^{n} \cdot D_{e f f \cdot} \cdot \frac{\partial X_{t}^{r, z}}{\partial r}\right) \\
\frac{d\left(\rho_{d m} \cdot\left(C p_{d m}+C p_{w} \cdot X_{t}^{r, z}\right) \cdot T p_{t}^{r, z}\right)}{d t}=\frac{1}{r^{n}} \cdot \frac{\partial}{\partial r}\left(r^{n} \cdot \lambda_{e f f} \cdot \frac{\partial T p_{t}^{r, z}}{\partial r}\right)
\end{gathered}
$$

where $X$ is the moisture content (d.b.), $r$ the radial position in the particle $(\mathrm{m}), z$ the particle position in the height of the bed $(\mathrm{m}), t$ the elapsed time $(\mathrm{s}), n$ the shape factor ( 1 or 2 for cylindrical or spherical symmetry, respectively), $D_{\text {eff }}$. the effective water diffusivity $\left(m^{2} . s^{-1}\right), T p$ the product temperature $(\mathrm{K})$, $\lambda_{\text {eff. }}$ the effective thermal conductivity $\left(W \cdot \mathrm{m}^{-1} \cdot K^{-1}\right), \rho_{d m}$ the density of the dry matter $\left(\mathrm{kg} \cdot \mathrm{m}^{-3}\right)$ and $C p_{d m}$ and $C p_{w}$ the heat capacities at constant pressure of dry matter and water, respectively $\left(J \cdot k g^{-1} \cdot K^{-1}\right)$, for the considered particle.

Temperature and moisture content within the particles were assumed to be initially uniform. In addition, boundary conditions are given in equations 7 to 10 .

$$
\begin{gathered}
\frac{\partial X_{t}^{0, z}}{\partial r}=0 \\
\frac{\partial T p_{t}^{0, z}}{\partial r}=0 \\
-\rho_{d m} \cdot \frac{\partial\left(D_{a p} \cdot X_{t}^{r_{\max }, z}\right)}{\partial r}=k_{m} \cdot \frac{M_{w}}{R} \cdot\left(\frac{a_{w} \cdot P v_{\text {sat. }}}{T p_{t}^{r_{\text {max }}, z}}-\frac{H R \cdot P v_{s a t}}{T a_{t}^{z}}\right)=\varphi_{m} \\
\lambda_{a p} \cdot \frac{\partial T p_{t}^{r_{\max }, z}}{\partial r}=h_{g l o b} \cdot\left(T a_{t}^{z}-T p_{t}^{r_{\max }, z}\right)-\varphi_{m} \cdot \Delta H_{v}=\varphi_{Q}
\end{gathered}
$$

where $k_{m}$ is the convective mass transfer coefficient $\left(m . s^{-1}\right), M_{w}$ the molar mass of water $\left(\mathrm{kg}_{\mathrm{mol}} \mathrm{mol}^{-1}\right)$, $R$ the perfect gas constant $\left(J . \mathrm{kg}^{-1} \cdot \mathrm{K}^{-1}\right), a_{w}$ the water activity of the particle $(\mathrm{Pa} / \mathrm{Pa}), \mathrm{P} v_{\text {sat }}$ the pressure of saturated vapor $(\mathrm{Pa}), \mathrm{RH}$ the relative humidity (decimal), $h_{\text {glob }}$ the external heat transfer coefficient including the heat transfer effectiveness by convection $\left(W \cdot m^{-2} \cdot K^{-1}\right), T a$ the air temperature $(K), \triangle H_{v}$ the 
enthalpy of vaporization of pure water $\left(J . \mathrm{kg}^{-1}\right), \varphi_{m}$ the mass flux density $\left(k g . s^{-1} \cdot \mathrm{m}^{-2}\right)$, and $\varphi_{Q}$ the heat flux density $\left(J . s^{-1} \cdot m^{-2}\right)$.

\subsubsection{For the air}

A microscopic balance was created in the air after each thin-layer crossing (equations 11 and 12). Air constant during a drying experiment.

$$
\begin{gathered}
\frac{d\left(\rho_{d a} \cdot Y_{t}^{z}\right)}{d t}=-\frac{\partial\left(\rho_{d a} \cdot v_{a} \cdot Y_{t}^{z}\right)}{\partial z}+\frac{\varphi_{m} \cdot a \cdot(1-\varepsilon)}{\varepsilon} \\
\frac{d\left(\rho_{d a} \cdot\left(C p_{d a}+Y_{t}^{z} \cdot C p_{v}\right) \cdot T a_{t}^{z}\right)}{d t}=-\frac{\partial}{\partial z}\left(\rho_{d a} \cdot\left(C p_{d a}+Y_{t}^{z} \cdot C p_{v}\right) \cdot T a_{t}^{z}\right) \\
-\frac{a \cdot(1-\varepsilon) \cdot \varphi_{Q}}{\varepsilon}
\end{gathered}
$$

where $\rho_{d a}$ is the density $\left(\mathrm{kg}_{\mathrm{m}} \mathrm{m}^{-3}\right)$ of dry air, $a$ the particle specific surface area (surface area per particle volume) $\left(m^{-1}\right), \varepsilon$ the bed porosity (decimal), $Y$ the moisture content (d.b.), Ta the temperature $(K)$, and $C p_{d a}$ and $C p_{v}$ the specific heat capacities at a constant pressure of dry air and water vapor, respectively $\left(J . k g^{-1} \cdot K^{-1}\right)$, for the considered air.

\subsection{Simulation and optimization}

The dynamic system consisted of a set of six Partial Differential Equations (PDEs 5 to 10). These equations were discretized in space into a set of Ordinary Differential Equations (ODEs) using an explicit finite volume scheme to be numerically integrated with respect to both time and space by the explicit embedded Runge-Kutta Cash-Karp (4, 5) method (Galassi et al., 2009) (for stiff systems).

To quantify the quality of the model predictions, the maxima of relative errors between experimental and simulation data were calculated according to equations 13 and 14 for thin-layer and deep-bed drying kinetics, respectively, valid for any time $t$. The aim was to minimize the maximum relative error (MINMAX algorithm) obtained on the measurable variables using the Nelder and Mead method (also known as Downhill Simplex method) (Nelder \& Mead, 1965).

$$
M R E_{T L}=\max \left(\left(\frac{\bar{X}_{s i m}^{t}-\bar{X}_{e x p}^{t}}{\bar{X}_{\text {exp }}^{t}}\right)^{2}\right)
$$




$$
M R E_{D B}=\max \left(\left(\frac{\overline{\bar{X}}_{\text {sim }}^{t}-\overline{\bar{X}}_{\text {exp }}^{t}}{\overline{\bar{X}}_{\text {exp }}^{t}}\right)^{2},\left(\frac{T a_{\text {out }, \text { sim }}^{t}-T_{\text {out }, \text { exp }}^{t}}{T a_{\text {out }, \text { exp }}^{t}}\right)^{2}\right)
$$

where $M R E_{T L}$ and $M R E_{D B}$ are the respective maximum relative errors for thin-layer and deep-bed kinetics, $\bar{X}_{\text {sim }} 1$ and $\left.\overline{\bar{X}}_{\text {sim }}\right|^{2}$ the simulated mean moisture content (d.b.), $\bar{X}_{\text {exp }}$ and $\overline{\bar{X}}_{\text {exp }}$ the experimental mean moisture content (d.b.) for thin-layer and deep-bed kinetics, respectively, and $T a_{\text {out, sim }}$ and $T a_{\text {out, exp }}$ the simulated and experimental output air temperature $\left({ }^{\circ} \mathrm{C}\right)$.

The model simulation required 13 parameters, each with a physical meaning. Some were measured in the laboratory (pellet dimensions and density, porosity of the bed, initial temperature and moisture content of the pellets), some were found in the literature (heat capacity, thermal conductivity, latent heat of vaporization, coefficients of heat and mass transfers by convection), and others identified by reverse methods (effective moisture diffusivity and water activity). All parameters required for the simulation (parameters of the model and numerical parameters of the solver) are summarized in table 5.

\section{Results and discussion}

\subsection{Sorption isotherms}

The sorption isotherms of two pellet formulations (P4C or P4R - $4 \mathrm{~mm}$ ) are presented in figure 2. There was no visible effect of temperature within the $\left[25^{\circ} \mathrm{C}-40^{\circ} \mathrm{C}\right]$ range (see figure 2. A). In addition, the standard deviation for the desorption and adsorption isotherm data of $\mathrm{P} 4 \mathrm{Rs}$ at $25^{\circ} \mathrm{C}$ was less than $0.5 \%$ between the two repetitions, demonstrating the reproducibility of our measurements. By comparing the sorption isotherms for the two formulations, one can observe that (see figure 2 B):

- when $a_{w}<0.7$, pellets for chickens were more hygroscopic than pellets for rabbits, meaning that the latter pellets had fewer sorption sites available at low water activity values;

- when $a_{w}>0.7$, pellets for rabbits were more hygroscopic than pellets for chickens, which is probably related to differences in the pellets' micro-porosity and composition. The water activity of mixtures is dependent on the fraction size of each ingredient (Hemmingsen et al., 2008). In particular, sugar beet pulp has a higher water-holding capacity than other ingredients at temperatures below $80^{\circ} \mathrm{C}$ (Hemmingsen et al. 2008, Serena \& Bach Knudsen, 2007). Sugar beet pulp was present only in P4Rs, and was probably responsible for their more-hygroscopic behavior at high water activity values.

\footnotetext{
${ }^{1} \bar{X}$ is the mean moisture content of each layer and is calculated as the volume-weighted average moisture content.

${ }^{2} \overline{\bar{X}}$, the mean moisture content within the bed, is calculated as the mean of the mean moisture content of each thin layer.
} 
However, it should be noted that variations in water activity had little influence on the accuracy of the drying model. We therefore disregarded discrepancies between sorption isotherm values for water activities below 0.8 in the framework of the drying or drying-cooling model simulation. As stated previously, two different correlations were used to fit the desorption isotherm data: the Chung-Pfost correlation Chung \& Pfost, from soybeans. Maier et al. then showed that the identified parameters $\left(p_{1}, p_{2}, p_{3}\right.$ and $p_{4}$ provided in equation 15 could be applied to different formulations of pellets for animal feed for relative humidity / water activity data between 20 and 90\% (Maier \& Bakker-Arkema, 1992).

$$
X_{e q}=0.375-0.0668 \cdot \ln \left(-1.98 \cdot(\Theta+24.6) \cdot \ln \left(a_{w}\right)\right)
$$

The identified parameters $\left(p_{1}, p_{2}, p_{3}\right.$ and $\left.p_{4}\right)$ allowed for a good agreement with experimental data for water activities between 0.4 and 0.8 , as shown in figure 3 . However this correlation gives non-zero (negative) values of $a_{w}$ when $X_{e q}=0$, which is physically not acceptable and can cause numerical divergence during the simulations.

$$
X_{e q}=\exp \left(\frac{\ln \left[-\ln \left(1.0-a_{w}\right) / 20.802\right]}{1.41185}\right)
$$

Instead, the identified parameters for the modified Henderson correlation (provided in equation 16) gave the effective moisture diffusivity for each new formulation or set of pelleting operating conditions, which explains the slight differences observed between correlations of coefficients of effective moisture diffusivity 
(see table 6).

\subsection{Final validation using drying and drying-cooling kinetics}

7 using the kinetics of the validation set of each pellet formulation. Mean errors of prediction for product moisture content were close to the actual uncertainties of the experimental data. Unsurprisingly, the largest errors were obtained from drying-cooling experiments in which the initial state of the pellets was known with less certainty.

difficulties of recording drying-cooling kinetics, these results justify the decision to characterize formulations of animal feed pellets using only drying experiments.

\section{Conclusion}

Several formulations of pellets for animal feed were characterized experimentally and using correlations found in the literature. The sorption isotherms for all the different pellets yielded mostly similar results, close to those given previously by (Maier \& Bakker-Arkema, 1992). The modified Henderson equation was preferred for numerical reasons and fitted onto the DVS data. To estimate the diffusion coefficient as a function of pellet moisture and temperature, several strategies were tested in the course of a larger project. 
These were all based on inverse methods, i.e. to identify $D_{\text {eff }}$ such that the simulated drying kinetics of the drying of pellets.

\section{References}

Abud-Archila, M., Courtois, F., Bonazzi, C., \& Bimbenet, J.-J. (2000). A compartmental model n of thin layer drying kinetics of rough rice. Drying Technology, 18, 1389-1414. URL: http:

ASAE, S. (2007). D245.6. moisture relationships of plant-based agricultural products. ASAE, . 
Bird, R. B., Stewart, W. E., \& Lightfoot, E. N. (2002). Transport phenomena. Wiley and Sons.

de Blank, H., Hendrix, E., Litjens, M., \& van Maaren, H. (1997). On-line control and optimisation of

[1] the pelleting process of animal feed. Journal of the Science of Food and Agriculture, 74, 13-19. URL: http://dx.doi.org/10.1002/(SICI) 1097-0010(199705) 74:1<13: :AID-JSFA755>3.0.CD;2-B, doi 10 . 1002/(SICI) 1097-0010(199705) 74:1<13: :AID-JSFA755>3.0.CO;2-B

Brook, R. C., \& Foster, G. H. (1981). Handbook of transportation and marketing in agriculture. chapter Drying, cleaning and condtionning. (pp. 63-110). CRC Press Inc. volume II. Field Crops.

Chung, D. S., \& Pfost, H. B. (1967). Adsorption and desorption of water vapor by cereal grains and their products. part i: Heat and free energy changes of adsorption and desorption. Transactions of the ASAE, $10,549-555$.

Courtois, F. (1991). Dynamic Modelling of Drying to Improve Processing Quality of Corn. Ph.D. thesis ENSIA, Massy, France. URL: http://tel.archives-ouvertes.fr/tel-00308506/.

Galassi, M., Theiler, J., \& Davies, J. (2009). Gnu scientific library reference manual. 3rd edition. Network Theory Ltd.

Hemmingsen, A. K. T., Stevik, A. M., Claussen, I. C., Lundblad, K. K., Prestlokken, E., Sorensen, M., \& Eikevik, T. M. (2008). Water adsorption in feed ingredients for animal pellets at different temperatures, particle size, and ingredient combinations. Drying Technology, 26, 738-748. doi:10.1080/ 07373930802046393

Henderson, S. M. (1952). A basic concept of equilibrium moisture. Agricultural Engineering, 33, 29-32.

Hill, C. A. S., Norton, A., \& Newman, G. (2009). The water vapor sorption behavior of natural fibers. Journal of Applied Polymer Science, 112, 1524-1537. URL: http://dx.doi.org/10.1002/app.29725 doi: $10.1002 /$ app.29725

Kelley, R. L., Maier, D. E., \& Bakker-Arkema, F. W. (1990). Evaluation of chilled cooling of feed pellets. American Society of Agricultural Engineers, 90, 13.

Lambert, C., Goujot, D., Romdhana, H., \& Courtois, F. (2015a). Toward a generic approach to build-up air drying models. Drying Technology, (p. 15). doi 10.1080/07373937.2015.1054510.

Lambert, C., Romdhana, H., \& Courtois, F. (2015b). Reverse methodology to identify moisture diffusivity during air-drying of foodstuffs. Drying Technology, 33, 1076-1085. URL: 
http://dx.doi.org/10.1080/07373937.2014.985792.

doi: $10.1080 / 07373937.2014 .985792$

arXiv:http://dx.doi.org/10.1080/07373937.2014.985792

Maier, D. E., \& Bakker-Arkema, F. W. (1992). The counterflow cooling of feed pellets. Journal of Agricultural Engineering Research, 53, 305-319. doi:10.1016/0021-8634(92)80089-B. 00072-2

Thomas, M., van Zuilichem, D., \& van der Poel, A. (1997). Physical quality of pelleted animal feed.

\section{S0377-8401(96)01058-9}

Thompson, T. L. (1968). Mathematical simulation of corn drying: A new model. Transactions of the American Society of Agricultural Engineers, 24, 582-586.

tion and quality of feed pellets. Animal Feed Science and Technology, 18, 1 - 17. URL: http://www. 


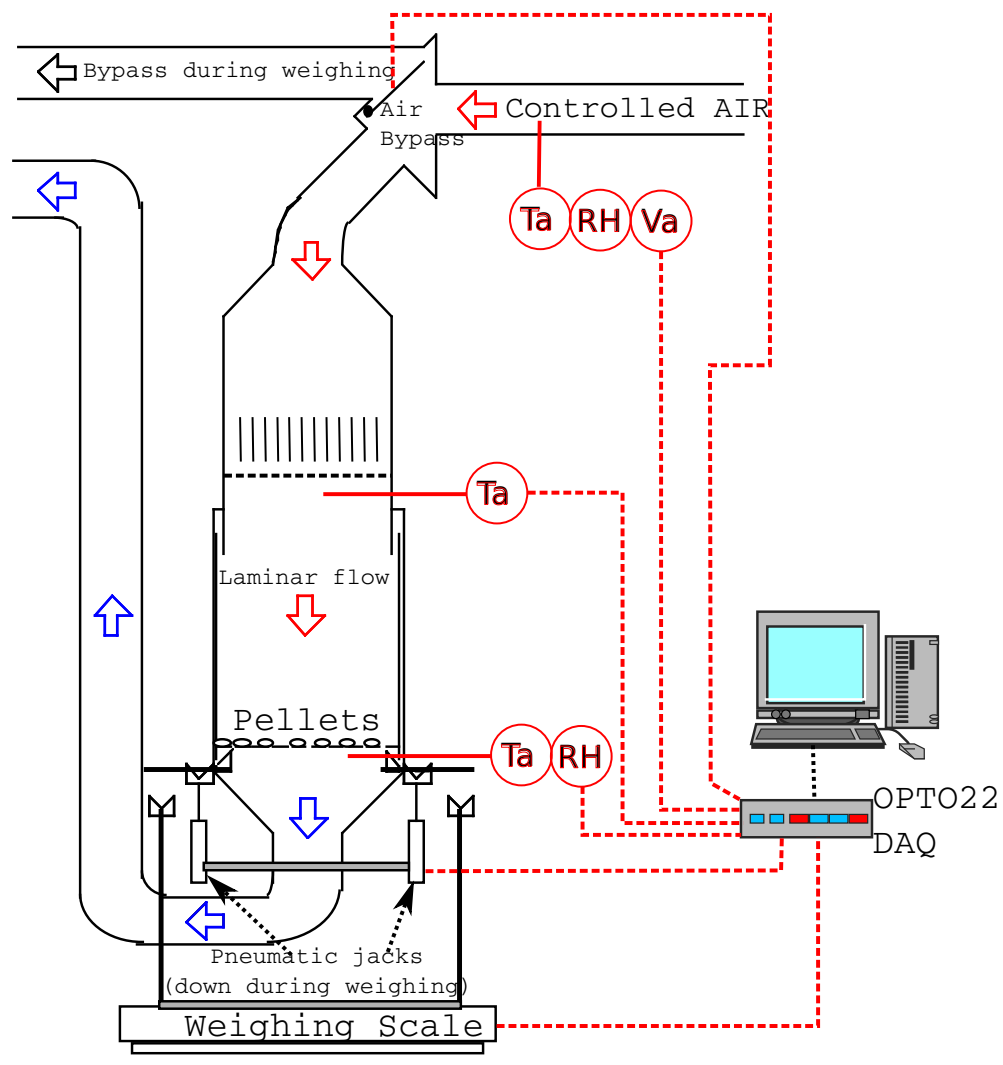

Figure 1: Schematic view of the drying pilot 
(A)

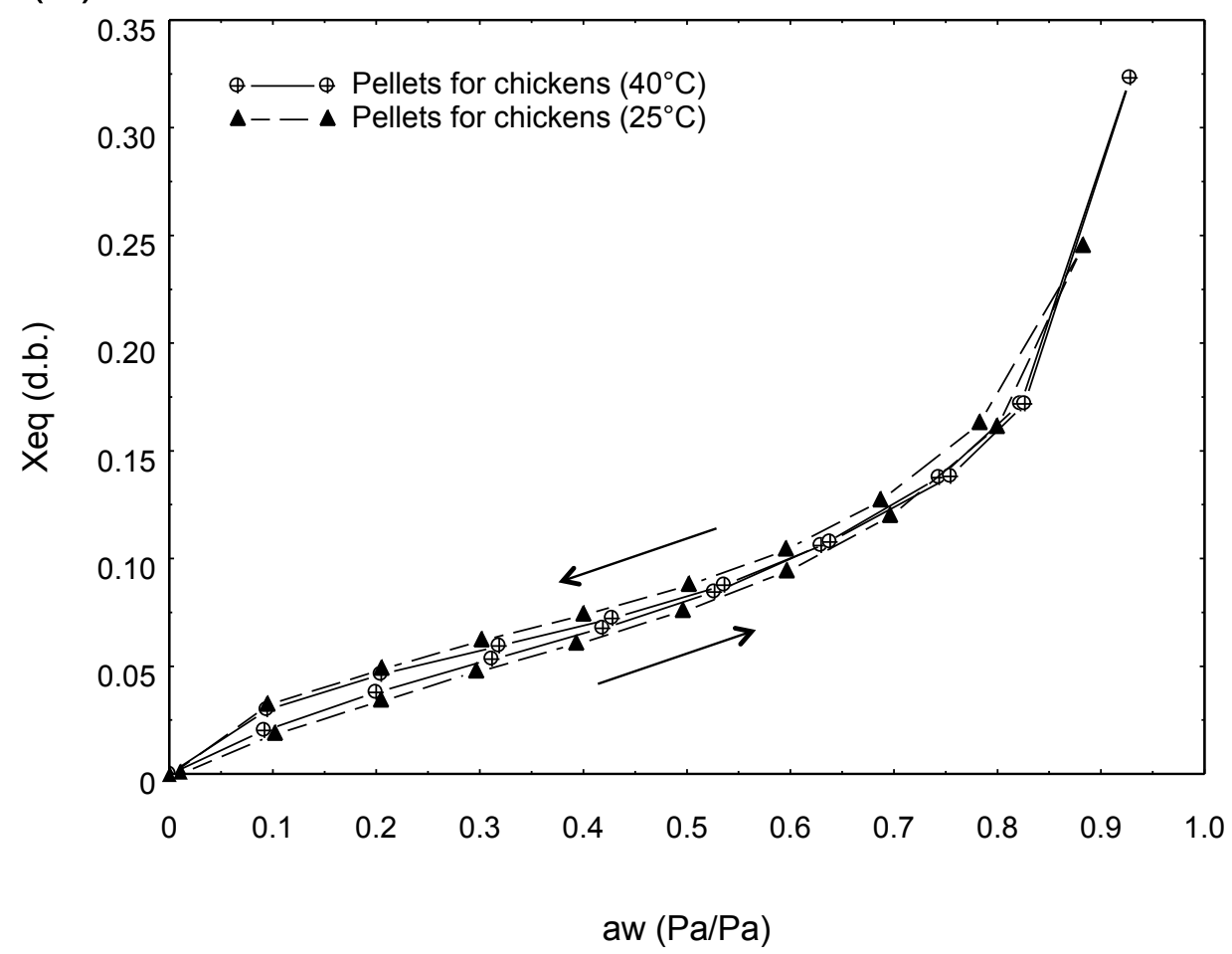

(B)

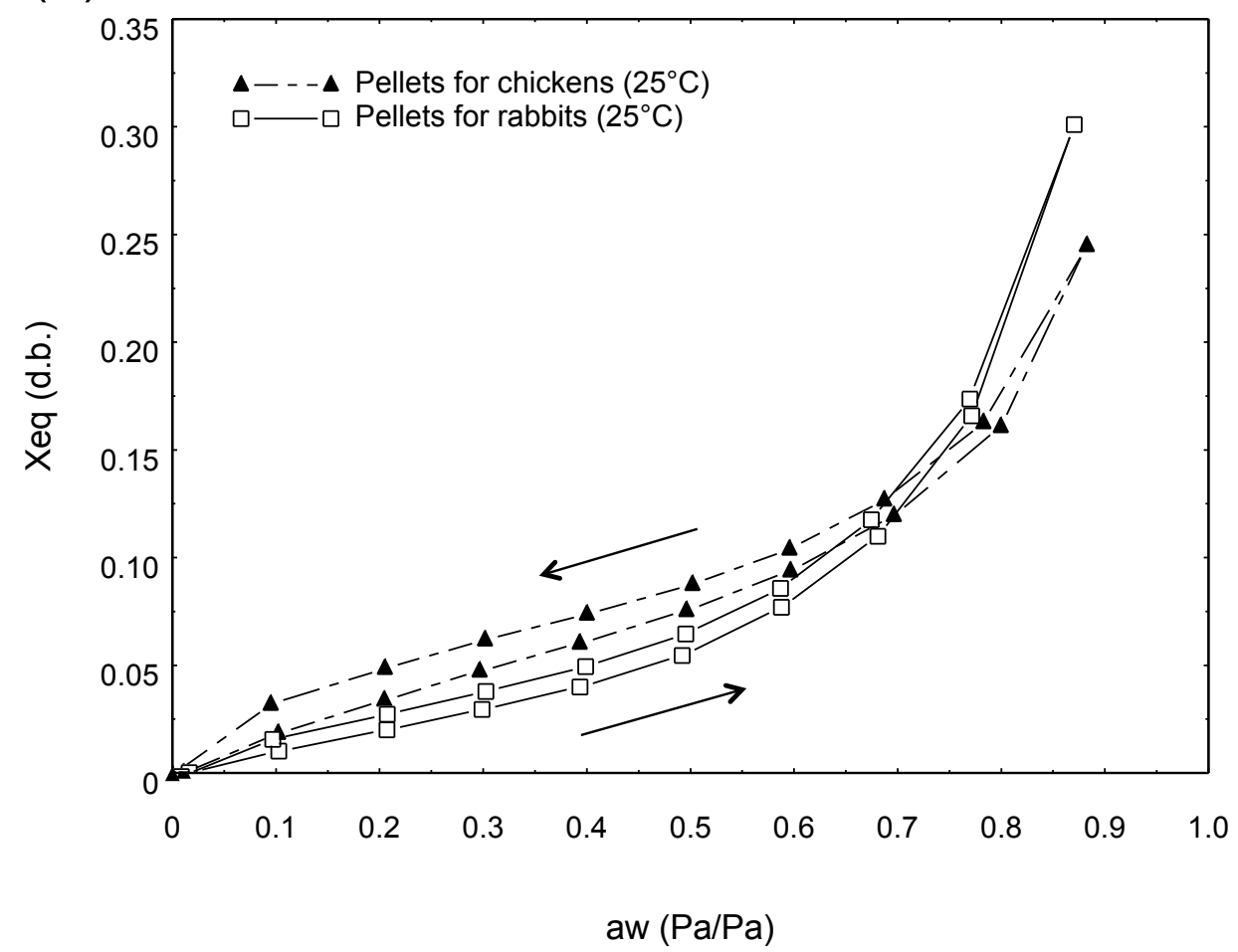

Figure 2: Sorption isotherms of pellets. (A) Effect of temperature on equilibrium moisture content, P4C pellets for chickens. (B) Effect of pellet formulation on equilibrium moisture content at $25^{\circ} \mathrm{C}$. ( $\rightarrow$ adsorption curves), $(\leftarrow$ desorption curves). 


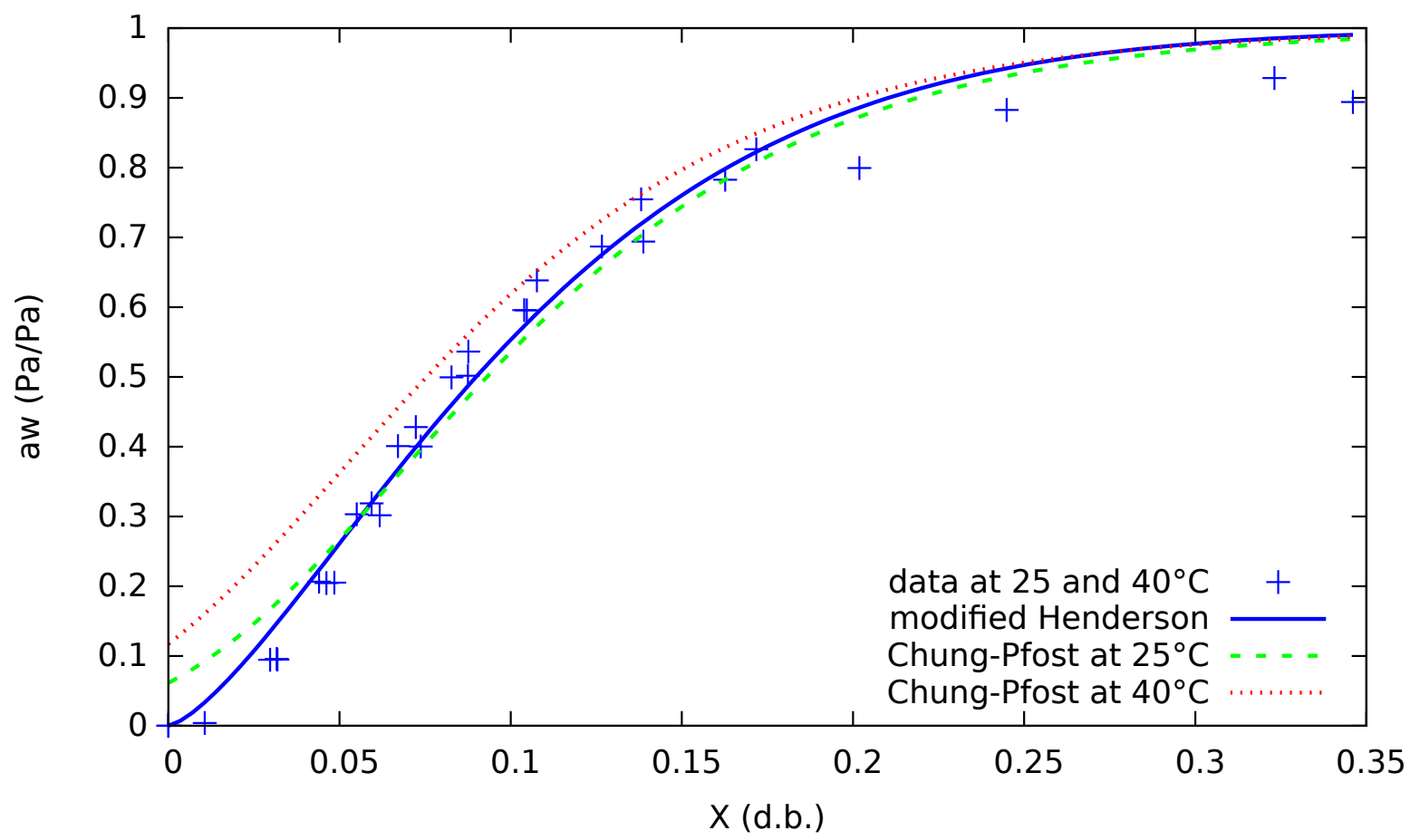

Figure 3: Fitting of sorption isotherms of pellets for rabbits $(\mathrm{P} 4 \mathrm{R}-4 \mathrm{~mm})$ at $25^{\circ} \mathrm{C}$ and pellets for chickens $(\mathrm{P} 4 \mathrm{C})$ at $25^{\circ} \mathrm{C}$ and $40^{\circ} \mathrm{C}(+)$, with Henderson modified correlation (continuous line) (Henderson 1952) and Chung-Pfost correlation (Chung \& Pfost 1967) at $25^{\circ} \mathrm{C}$ (dotted line) and $40^{\circ} \mathrm{C}$ (tiny dotted line).
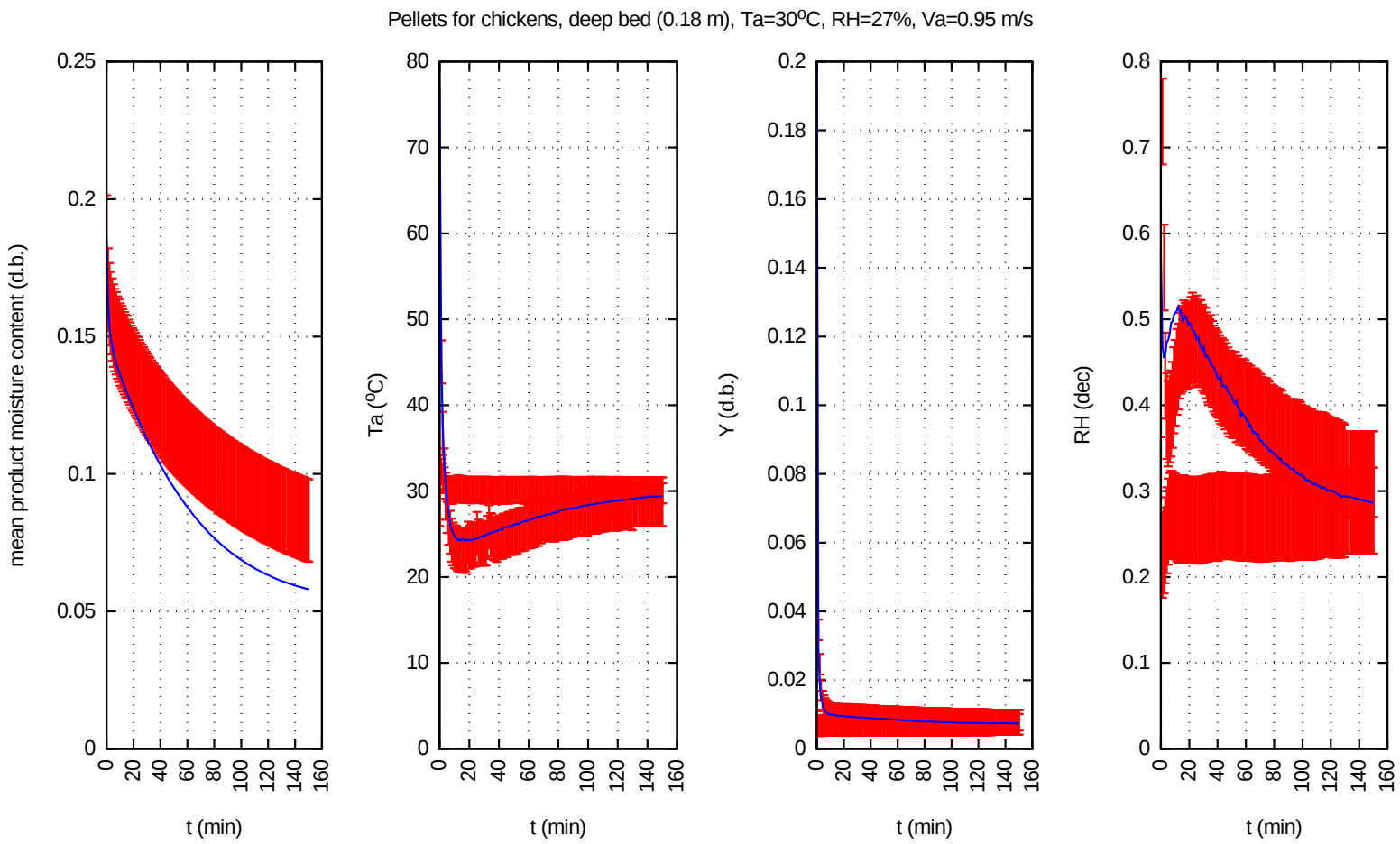

Figure 4: Comparison of experimental (dots with error bars) and simulated (-) data of deep-bed drying-cooling kinetics of pellets for chickens (validation set). 

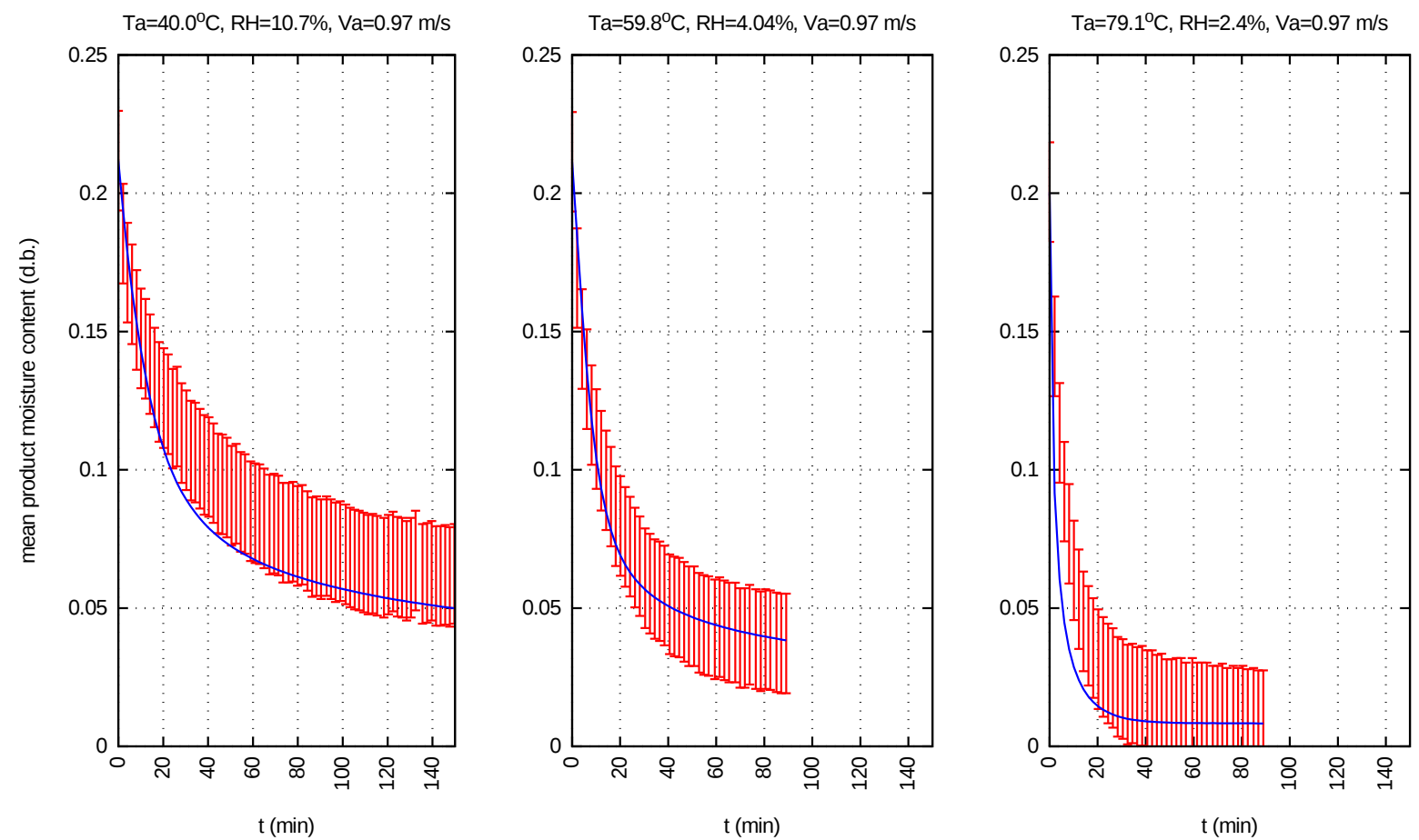

Figure 5: Comparison of experimental (dots with error bars) and simulated (-) data of thin-layer drying kinetics of the P4R $4 \mathrm{~mm}$ pellets for rabbits (validation set)
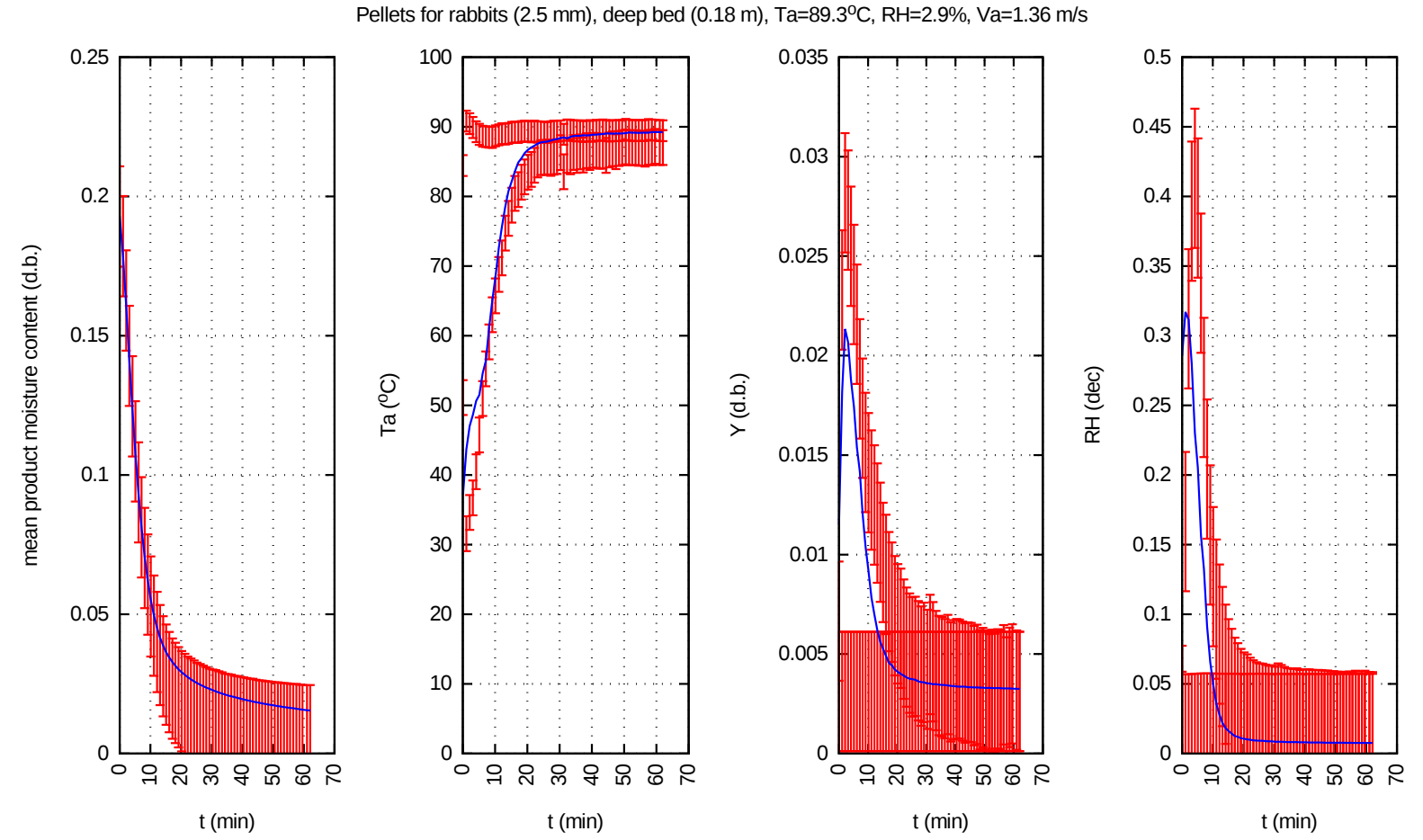

Figure 6: Comparison of experimental (dots with error bars) and simulated (-) data of deep-bed drying kinetics of the P4R $2.5 \mathrm{~mm}$ pellets for rabbits (validation set) 

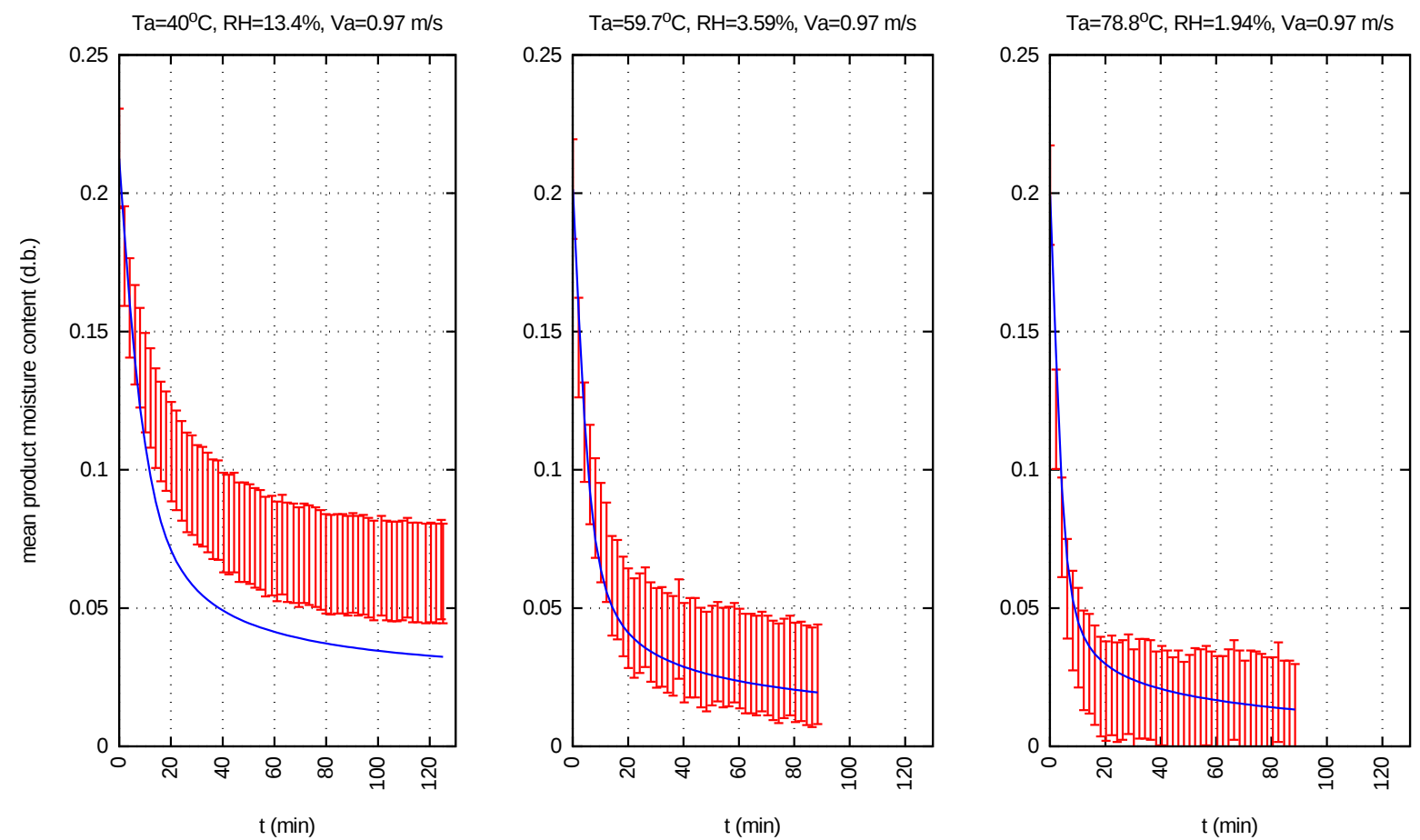

Figure 7: Comparison of experimental (dots with error bars) and simulated (-) data of thin-layer drying kinetics of the P4R $2.5 \mathrm{~mm}$ pellets for rabbits (validation set)

Table 1: Composition of the pellets for chickens and rabbits (P4R - $2.5 \mathrm{~mm}$ and P4R $-4 \mathrm{~mm}$ )

\begin{tabular}{|l|r|l|r|}
\hline \multicolumn{2}{|c|}{ Pellets for chickens } & \multicolumn{2}{|c|}{ Pellets for rabbits } \\
\hline Wheat & $40 \%$ & Wheat & $4.5 \%$ \\
Corn & $20 \%$ & Barley & $13.2 \%$ \\
Soybean cake & $30 \%$ & Soybean cake & $5.8 \%$ \\
Soybean seed & $4 \%$ & Soybean oil & $0.5 \%$ \\
Soybean oil & $3 \%$ & Grape pulp & $5 \%$ \\
Dicalcium phosphate & $1.15 \%$ & Sunflower cake & $8.5 \%$ \\
Calcium carbonate & $0.95 \%$ & Rape seed & $3.5 \%$ \\
Other & $0.9 \%$ & Milurex & $8.5 \%$ \\
& & Cane molasses & $6 \%$ \\
& & Sugar pulp & $15 \%$ \\
& & Alfalfa & $23.6 \%$ \\
& & Straw & $3.5 \%$ \\
& & Calcium carbonate & $0.9 \%$ \\
& & Other & $1.5 \%$ \\
\hline Total & $100 \%$ & Total & $100 \%$ \\
\hline
\end{tabular}


Table 2: Dry matter composition of pellets for chickens and rabbits (P4R - 2.5 mm and P4R - $4 \mathrm{~mm}$ ) Composition (\% d.b.)

\begin{tabular}{lcc} 
& Pellets for chickens & Pellets for rabbits \\
\hline Proteins & 20.9 & 15.8 \\
Lipids & 19.1 & 3.9 \\
Total sugar & 54.5 & 70.5 \\
Ashes & 5.5 & 9.8 \\
\hline
\end{tabular}

Table 3: Experimental conditions of the drying and the drying-cooling of pellets for chickens and rabbits

\begin{tabular}{|c|c|c|c|c|}
\hline & & & $\begin{array}{l}\text { Pellets for } \\
\text { chickens }\end{array}$ & $\begin{array}{l}\text { Pellets for } \\
\text { rabbits }\end{array}$ \\
\hline \multirow[t]{2}{*}{ Drying kinetics } & $\begin{array}{l}\text { Thin layer } \\
\text { experiments }\end{array}$ & $\begin{array}{c}\frac{T p_{0}}{X_{0}} \\
v_{a} \\
T a_{0}^{0}\end{array}$ & $\begin{array}{c}\approx 20{ }^{\circ} \mathrm{C} \\
0.204 \mathrm{~d} . \mathrm{b} . \\
1 \mathrm{~m} . \mathrm{s}^{-1} \\
30-90^{\circ} \mathrm{C}\end{array}$ & $\begin{array}{c}\approx 20{ }^{\circ} \mathrm{C} \\
0.208 \mathrm{~d} . \mathrm{b} . \\
1 \mathrm{~m} . \mathrm{s}^{-1} \\
40-80{ }^{\circ} \mathrm{C}\end{array}$ \\
\hline & $\begin{array}{l}\text { Deep bed } \\
\text { experiments }\end{array}$ & $\begin{array}{c}\text { height } \\
\frac{T p_{0}}{\bar{X}_{0}} \\
v_{a} \\
T a_{0}^{0}\end{array}$ & $\begin{array}{l}\approx 18 \mathrm{~cm} \\
\approx 20{ }^{\circ} \mathrm{C} \\
0.204 \mathrm{~d} \cdot \mathrm{b} . \\
1 \mathrm{~m} \cdot \mathrm{s}^{-1} \\
\approx 90{ }^{\circ} \mathrm{C}\end{array}$ & $\begin{array}{c}10-18 \mathrm{~cm} \\
\approx 20{ }^{\circ} \mathrm{C} \\
0.208 \mathrm{~d} . \mathrm{b} . \\
0.7-2.4 \mathrm{m.s} \\
60-90{ }^{\circ} \mathrm{C}\end{array}$ \\
\hline $\begin{array}{c}\text { Drying-cooling } \\
\text { kinetics }\end{array}$ & $\begin{array}{l}\text { Deep bed } \\
\text { experiments }\end{array}$ & $\begin{array}{l}\text { height } \\
T p_{0} \\
\overline{\bar{X}}_{0} \\
v_{a} \\
T a_{0}^{0}\end{array}$ & $\begin{array}{l}\approx 18 \mathrm{~cm} \\
\approx 60{ }^{\circ} \mathrm{C} \\
0.188 \mathrm{~d} . \mathrm{b} . \\
1 \mathrm{~m} . \mathrm{s}^{-1} \\
\approx 30{ }^{\circ} \mathrm{C}\end{array}$ & \\
\hline
\end{tabular}

$\overline{X_{0}}, \overline{\overline{X_{0}}}$ Initial mean moisture content of the pellets respectively in the case of thin layer and deep bed kinetics

$T a_{0}^{0}$ Initial inlet air temperature

$v_{a}$ Inlet air velocity

$T p_{0}$ Initial temperature of the bed of pellets 


\begin{tabular}{|c|c|c|c|}
\hline & $\begin{array}{l}\text { Pellets for } \\
\text { chickens }\end{array}$ & $\begin{array}{l}\text { Pellets for } \\
\text { rabbits } \\
(2.5 \mathrm{~mm})\end{array}$ & $\begin{array}{l}\text { Pellets for rabbits } \\
(4 \mathrm{~mm})\end{array}$ \\
\hline $\begin{array}{l}\text { Identification } \\
\text { set }\end{array}$ & $\begin{array}{l}\text { One set of deep } \\
\text { bed kinetics (inlet } \\
\text { air velocity fixed at } \\
1 \mathrm{~m}^{-1} \text {, inlet air } \\
\text { temperature at } \\
90{ }^{\circ} \mathrm{C} \text {, and bed } \\
\text { height at } 18 \mathrm{~cm} \text { ) }\end{array}$ & $\begin{array}{l}\text { Two thin layer } \\
\text { kinetics } \\
\text { (inlet air velocity } \\
\text { fixed at } 1 \mathrm{~m} \cdot \mathrm{s}^{-1} \text {, } \\
\text { inlet air } \\
\text { temperature } \\
\text { respectively at } 40 \\
\text { and } 80{ }^{\circ} \mathrm{C} \text { ) }\end{array}$ & $\begin{array}{l}\text { Two deep bed kinetics } \\
\text { (inlet air velocity fixed } \\
\text { at } 1 \mathrm{~m} \cdot \mathrm{s}^{-1} \text {, inlet air } \\
\text { temperature } \\
\text { respectively at } 60 \text { and } \\
80{ }^{\circ} \mathrm{C} \text {, and bed height } \\
\text { at } 18 \mathrm{~cm} \text { ) }\end{array}$ \\
\hline Validation set & $\begin{array}{l}\text { All thin layer and } \\
\text { drying-cooling } \\
\text { kinetics }\end{array}$ & $\begin{array}{l}\text { All other thin layer } \\
\text { kinetics and deep } \\
\text { bed kinetics }\end{array}$ & All thin layer kinetics \\
\hline
\end{tabular}

Table 5: Physical properties of pellets and parameters used in simulation

\begin{tabular}{|c|c|c|c|}
\hline \multirow{2}{*}{ Property } & \multicolumn{3}{|c|}{ Equation or value } \\
\hline & $\begin{array}{c}\text { Pellets for } \\
\text { chickens }\end{array}$ & $\begin{array}{l}\text { Pellets for } \\
\text { rabbits } \\
\text { ("2.5 mm") }\end{array}$ & $\begin{array}{l}\text { Pellets for } \\
\text { rabbits } \\
\text { ("4 } \mathrm{mm} \text { ") }\end{array}$ \\
\hline Radius & $2.14 \mathrm{~mm}$ & $0.95 \mathrm{~mm}$ & $2.18 \mathrm{~mm}$ \\
\hline Characteristic length & $6.09 \mathrm{~mm}$ & $6.14 \mathrm{~mm}$ & $9.02 \mathrm{~mm}$ \\
\hline Density & $1,325 \mathrm{~kg} \cdot \mathrm{m}^{-3}$ & $1,170 \mathrm{~kg} \cdot \mathrm{m}^{-3}$ & $1,183 \mathrm{~kg} \cdot \mathrm{m}^{-3}$ \\
\hline Porosity of the deep bed & 0.56 & 0.58 & 0.56 \\
\hline Initial temperature & & $20{ }^{\circ} \mathrm{C}$ & \\
\hline Initial moisture content & 0.204 d.b. & 0.211 d.b. & 0.202 d.b. \\
\hline Heat capacity & \multirow{7}{*}{\multicolumn{3}{|c|}{ 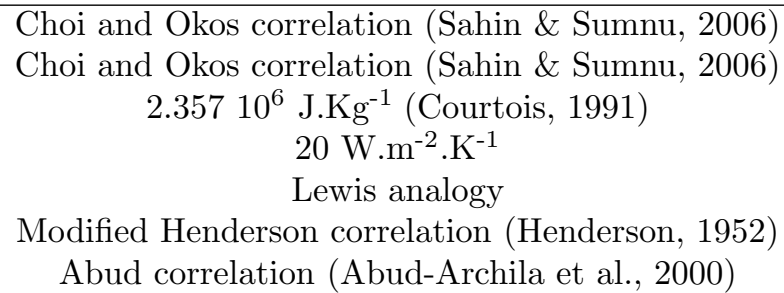 }} \\
\hline Thermal conductivity & & & \\
\hline Latent heat of vaporization & & & \\
\hline Coefficient of heat transfer by convection & & & \\
\hline Coefficient of mass transfer by convection & & & \\
\hline Water activity & & & \\
\hline Effective moisture diffusivity & & & \\
\hline Number of layer within the particle & \multicolumn{3}{|c|}{10} \\
\hline Height of the thin layer within the bed & \multicolumn{3}{|c|}{$1 \mathrm{~mm}$} \\
\hline Absolute tolerance & \multicolumn{3}{|c|}{$10^{-6}$} \\
\hline Relative tolerance & \multicolumn{3}{|c|}{$10^{-6}$} \\
\hline Initial time variation & \multicolumn{3}{|c|}{$10^{-3}$} \\
\hline
\end{tabular}

Table 6: Identified values of effective moisture diffusivity for each formulation and geometry of pellets

\begin{tabular}{|l|c|c|c|}
\cline { 3 - 4 } \multicolumn{1}{c|}{} & \multirow{2}{*}{ Pellets for chickens } & \multicolumn{2}{|c|}{ Pellets for rabbits } \\
\cline { 3 - 4 } \multicolumn{1}{c|}{} & & $\mathrm{P} 4 \mathrm{R}-2.5 \mathrm{~mm}$ & $\mathrm{P} 4 \mathrm{R}-4 \mathrm{~mm}$ \\
\hline$d_{1}$ & 22.153 & 25.177 & 26.694 \\
\hline$d_{2}$ & 0.2017 & 1.452 & 1.736 \\
\hline
\end{tabular}


Table 7: Mean absolute errors observed on product mean moisture content and outlet air temperature of the kinetics of the validation set

\begin{tabular}{|c|c|c|c|c|c|c|c|}
\hline & \multicolumn{2}{|c|}{$\begin{array}{l}\text { Mean absolute } \\
\text { error }\end{array}$} & \multicolumn{4}{|c|}{$\begin{array}{l}\text { Operating conditions of the } \\
\text { kinetics of the validation set }\end{array}$} \\
\hline & & $\begin{array}{c}\bar{X} \text { or } \overline{\bar{X}} \\
\text { (d.b.) }\end{array}$ & $\begin{array}{r}T a_{\text {out }} \\
\left({ }^{\circ} \mathrm{C}\right)\end{array}$ & $\begin{array}{l}T a_{\text {in }} \\
\left({ }^{\circ} \mathrm{C}\right)\end{array}$ & $\begin{array}{c}v_{a} \\
\left(m . s^{-1}\right)\end{array}$ & $\begin{array}{r}\text { height } \\
(\mathrm{cm})\end{array}$ & $\begin{array}{l}T p_{0} \\
\left({ }^{\circ} \mathrm{C}\right) \\
\end{array}$ \\
\hline \multirow{2}{*}{ Pellets for chickens } & TL & $<0.016$ & & $30-70$ & 1 & & 20 \\
\hline & $\mathrm{DC}$ & 0.022 & 0.8 & 30 & 1 & 18 & 60 \\
\hline $\begin{array}{l}\mathrm{P} 4 \mathrm{R}-4 \mathrm{~mm} \text { geometry } \\
\text { of pellets for rabbits }\end{array}$ & TL & $<0.012$ & & $40-80$ & 1 & & 20 \\
\hline \multirow{2}{*}{$\begin{array}{l}\mathrm{P} 4 \mathrm{R}-2.5 \mathrm{~mm} \\
\text { geometry of pellets for } \\
\text { rabbits }\end{array}$} & TL & $\begin{aligned} & 0.032 \\
< & 0.014\end{aligned}$ & & $\begin{array}{c}40 \\
60-80\end{array}$ & 1 & & 20 \\
\hline & $\mathrm{DB}$ & $<0.014$ & $<4$ & $60-90$ & $0.7-2$ & $10-18$ & 20 \\
\hline
\end{tabular}

TL Thin layer kinetics

DC Drying-cooling kinetics

DB Deep bed kinetics

$\bar{X}$ Mean moisture content of the particles (case of thin layer kinetics)

$\overline{\bar{X}}$ Mean moisture content of the particles within the bed (case of deep bed kinetics)

$T a_{\text {out }}$ Outlet air temperature

$T a_{i n}$ Inlet air temperature

$v_{a}$ Inlet air velocity

$T p_{0}$ Initial temperature of the bed of pellets 